\title{
Effect of Operating Temperatures and Working Pairs on Performance of Solar Adsorption Cooling System
}

\author{
Ghrici Adenane*, Benramdane Mohammed, Ghernaout Mea \\ ETAP Laboratory, Department of Mechanical Engineering, Faculty of Technology, Tlemcen University, Tlemcen 13000 , \\ Algeria
}

Corresponding Author Email: adnane.onlytheone@gmail.com

https://doi.org/10.18280/ijht.390426

Received: 15 March 2021

Accepted: 13 July 2021

\section{Keywords:}

solar cooling, Adsorption refrigeration,

Thermodynamic parameters, COP

\begin{abstract}
Renewable energies including solar energy requirements for refrigeration and air conditioning are increasingly gaining interest due to the refrigerants friendly to the environment. However, it was found that these technologies have some limitations like the low performance and their high cost. This paper proposes a comparative study of a solar adsorption refrigeration machine. The study consists in determining the influence of thermodynamic parameters of operation on the performance of the system. This is based on a thermodynamic model using different types of adsorbent / adsorbate pairs. The main parameters considered in this study are: temperature of generation, evaporation, maximum heating temperature, condensation pressure as well as the type of the pair used: activated carbon / methanol and zeolite / water. Simulations for different thermodynamic parameters show that the COP is very sensitive to the generation and evaporation temperatures as well as the maximum heating temperature, on the other hand it was slightly influenced by the condensation pressure. The results obtained have shown that the $\mathrm{AC} /$ methanol pair is more profitable than the zeolite / water pair.
\end{abstract}

\section{INTRODUCTION}

Solar (solar photovoltaic, solar thermal), hydropower, wind, biomass and geothermal energy are inexhaustible flows compared to "stock energies" from fossil fuel deposits in the process of becoming rare: oil, coal, natural gas [1]. The conversion of solar energy into cooling has become one of the major applications and consists of two major types which are photovoltaic and thermal cooling, this has several methods of which gas sorption is the dominant one in air conditioning and solar refrigeration [2].

Absorption [3-6] is the main technology while adsorption $[7,8]$ is the second main technology of thermal cooling; this made it receiving a great deal of interest due to their refrigeration capacities in comparison with photovoltaic systems [9, 10] which are offered for low-capacity air conditioning applications and our work deals with solar adsorption refrigeration systems in its basic cycle. This technology is mainly used for ice making, air conditioning and refrigeration. The main advantages of adsorption system are: ability to work with wide range of driving temperatures, noiseless, non-corrosive, and environmentally friendly refrigerants [11-13]. However, several factors have been discovered and appear to be disadvantages for this type of refrigeration such as intermittent solar energy, low coefficient of performance compared to those with vapor compression cycle, high cost of adsorber chillers, poor heat transfer performance, the size of this type of technology and long adsorption/desorption time, hence the need to improve performance of solar adsorption cooling taking into account the cost factor.

Due to their high cost, energetic systems powered by solar energy and solar adsorption cooling systems precisely, modelisation and numerical simulation presents reliable solution to study, test, evaluate and improve this type of systems. thus, for this purpose several researches work for simulation have been proposed and developed in which consist in testing the influence of numerous parameters that can be geometric, thermodynamic or temporal variables, in the hope of solving the technical, economic, environmental problems, and achieve high performance and low cost [13]. An experimental platform was carried out by Najah et all combining an internal combustion gas engine with adsorption machine and developed a simulation model confronted with experimental measurements [14]. They found that the outlet temperature of the collector increases with increasing the solar radiation. The COP and cooling power of the chiller achieved was 0.62 and $5.64 \mathrm{KW}$. the thermal conductivity of adsorbent, the flow rate and the inlet temperature of the heat transfer fluid were simulated and analyzed by $\mathrm{Xu}$ [15]. Douss and Meunier [16] studied the effect of operating temperatures on the coefficient of performance of active carbon -methanol system. The results showed that The COP was seen to be very sensitive to the evaporating and adsorbing temperatures. A numerical simulation for adsorption solar cooling system with activated carbon -methanol pair was carried out by Leite et al. [17]. The effect of TIM cover system was studied and found that is $40 \%$ more efficient then the single cover with COP reached 0.13 and corresponds to $7-10 \mathrm{~kg} /$ day of ice production. Ambarita and Kawai [18] tested experimentally the type and amounts of adsorbents filled in a solar adsorption refrigeration system using activated ammonia AA and activated carbon AC. The results showed that a higher COP of 0.074 was been found with utilizing of adsorbent of $100 \%$ AC. Brites et al. [19] 
developed a numerical study to determine the influence of the design parameters on the overall performance of a solar adsorption refrigerator using flat plate collector and silica gelwater pair. The main parameters in this study were the mass of silica-gel, the number of metallic fins in the silica-gel bed, the orientation of the solar collector (azimuth angle). The influence of collector area and cycle time on performance of a single-stage, two-bed adsorption chiller is studied by Kumar et al. They used dynamic model with silica gel / water in two different days in summer and winter to study the performances. They found that both daily average and cyclic average COP increase with increase in solar collector area and the same thing for the cycle time [20]. Cherrad [21] studied the effect of heating time of the adsorber/collector on the performance of a solar adsorption refrigerator. They developed a numerical model to predict the amounts of heat transfer in the adsorber/collector. The shorter heating time corresponds to higher efficiencies of adsorber/collector and the maximum COP reached was 0.11 . Fernandes et al. [22] presented a state of the art of different operating pairs and technologies with a basic cycle for solar adsorption refrigeration system. Chekirou et al. [23] evaluated the performance of an adsorption cooling system powered by solar energy with activated carbonmethanol as a working pair and using a numerical model. They discussed the effect of the collector surface area and the operating temperatures. The performance described in this study was solar and thermal coefficient of performance. The results showed that both coefficients of performance decrease with the increase of solar collector area, and strongly depends on the operating temperatures considered [23]. The effect of solar collector area and its configuration, solar total irradiation on system's performance was studied by Chekirou et al. [24]. They concluded that both the COP and cooling capacity decrease when solar collector area is increased while the utilization of TIM for collector insulation shows best results then the double and single glazed configurations. Furthermore, COP also increase when the total solar irradiance is increased. Chua et al. [25] developed a transient model for tow bed silica gel adsorption chiller. He discussed the effect of switching and cycle time on the chiller performance. The results showed that a maximal COP of 0.56 can be attend by a chosen $450 \mathrm{~s}$ a cycle time. Moreover, a $11 \%$ increase in COP can be achieved by a $0.4 \%$ reducing in maximal cooling capacity. Tubreoumya et al. [26] used a dynamic modelling for simulation of an adsorption solar refrigeration system with silica gel -water as working pair. They analyzed the influence of the adsorbate/adsorbent working pairs, the solar flux, the ambient temperature on the adsorption and desorption process. Liu et al. [27] evaluated experimentally the effect of adsorption time on the performance of solar adsorption cooling system using silica gel -water as working pair, in which the results showed that the optimal COP was 0.258 for an adsorption time of $45 \mathrm{~min}$. In addition, a comparison between two working pairs: silica gel to the SAPO-34 zeolite was made. Ji et al. [28] designed, analyzed and optimized a large-diameter aluminum-alloy finned-tube adsorbent bed collector for enhancing the heat transfer and reducing the uneven temperature distribution in the collector/adsorber. The adsorbent bed efficiency was improved between $31.64 \%$ and $42.7 \%$, the maximum COP was 0.122 and maximum daily ice-making can achieve $6.5 \mathrm{~kg}$. The choice of the adsorbent / adsorbate pairs appeared essential and decisive on the performance of the system [21, 27, 29].

From literatures above, it can be found that a good improvement of technical problem of solar adsorption cooling systems can be brought. Hence, high cooling capacity, coefficient of performance and adsorption chiller temperature can be achieved by a good analyzing of the influence of all type of parameters theoretically, then approve it experimentally in manufactures.

In view of this, a thermodynamic model is proposed to evaluate the solar adsorption cooling system based on the typical basic cycle. The method proposes a study of the influence of thermodynamic cycle parameters and the working pair at the same time on the coefficient of performance.

In this paper, thermodynamic results were presented to see the effect of coefficient of performance as a function of the pressure and temperature operating parameters and compared for two pairs chosen AC / methanol and Zeolite / water and that for a solar refrigeration system at conventional adsorption.

\section{SYSTEM DESCRIPTION AND WORKING PRINCIPAL}

The studied system is a solar adsorption refrigerator in its simplest form, the schematic diagram of which is shown in Figure 1. It has been shown in detail about the various components of a solar adsorption refrigeration system as well as the working principle in Ref. [30]. A solar adsorption refrigerator based on the basic adsorption refrigeration cycle does not require any mechanical or electrical energy, just thermal energy, and it operates intermittently according to the daily cycle [8].

The basic cycle process of adsorption solar refrigeration systems is as follows:

$1-2$ : Isosteric heating

2-3: Isobaric heating

3-4: Isosteric cooling

4-1: Isobaric cooling

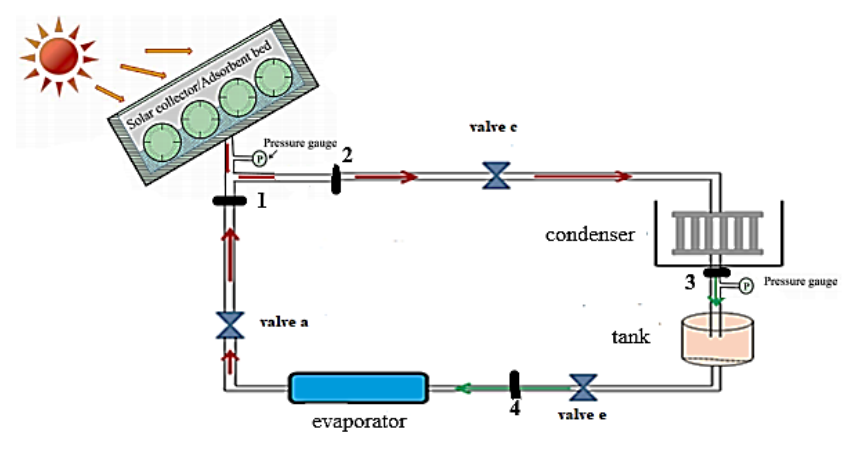

Figure 1. Schematic diagram of the solar adsorption refrigeration system

The cycle begins at point 1 (Figure 2), when the system is at the adsorption temperature $\mathrm{T}_{\mathrm{a}}$ and at a low pressure $\mathrm{P}_{\mathrm{e}}$ (evaporation pressure), but the concentration of the refrigerant is maximum $\mathrm{X}_{\max }$. The adsorber receives a quantity of thermal heat $\mathrm{Q}_{\mathrm{d} 1}$ which increases the pressure and temperature along the isosteric line 1-2 (at constant concentration). At point 2, the heating continues and by increasing the temperature and desorption begins, the generation of steam occurs receiving a quantity of heat $\mathrm{Q}_{\mathrm{d} 2}$ the pressure remains constant along the isobar line 2-3 while the concentration decreases to $X_{\min }$. the vapor generated is liquefied by the condenser following the isosteric line 3-4 releasing a quantity of heat $\mathrm{Q}_{\mathrm{cd}}$ at a constant 
concentration $\mathrm{X}_{\min }$ and at a condensing temperature $\mathrm{T}_{\mathrm{c}}$. During transformation 4-1, the condensed refrigerant following the isosteric line 3-4 releasing a quantity of heat $\mathrm{Q}_{\mathrm{cd}}$ at a constant concentration $\mathrm{X}_{\min }$ and at a condensing temperature $\mathrm{T}_{\mathrm{c}}$. During transformation 4-1, the condensed refrigerant flows into the evaporator and the pressure decreases to the evaporating pressure Pe and the adsorption phase occurs by absorbing a quantity of heat $\mathrm{Q}_{\mathrm{ev}}$ bringing the vapor back to liquid and producing the effect of cold. The evaporated refrigerant flows to the adsorber to be adsorbed and accumulated causing its concentration to increase to $X_{\max }$ at point 1 and is cooled to the adsorption temperature $\mathrm{T}_{\mathrm{a}}$ and the cycle begins again.

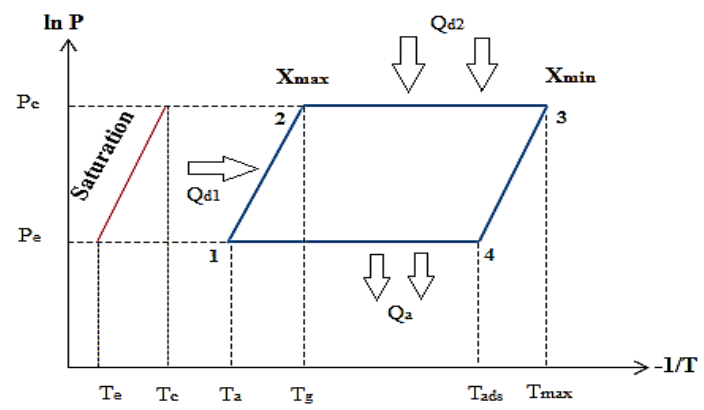

Figure 2. Theoretical cycle of the adsorption solar refrigeration system (Clapeyron diagram)

\section{THERMODYNAMIC STUDY}

The refrigeration capacity, the heating capacity and the coefficient of performance are given by Lu et al. [31] in the Eqns. (1) to (3).

$$
\begin{gathered}
\mathrm{Q}_{\mathrm{e}}=\dot{\mathrm{m}}_{\mathrm{ch}} \mathrm{c}_{\mathrm{w}}\left(\mathrm{T}_{c h, i}-\mathrm{T}_{c h, o}\right) \\
\mathrm{Q}_{\mathrm{h}}=\dot{\mathrm{m}}_{\mathrm{h}} \mathrm{c}_{\mathrm{w}}\left(\mathrm{T}_{h, i}-\mathrm{T}_{h, o}\right) \\
\operatorname{COP}=\frac{\dot{\mathrm{m}}_{\mathrm{ch}} \mathrm{c}_{\mathrm{W}}\left(\mathrm{T}_{c h, i}-\mathrm{T}_{c h, o}\right)}{\dot{\mathrm{m}}_{\mathrm{h}} \mathrm{c}_{\mathrm{w}}\left(\mathrm{T}_{h, i}-\mathrm{T}_{h, o}\right)}
\end{gathered}
$$

For constant physical properties of fluids, the mass enthalpy is defined:

$$
\Delta \mathrm{h}=c p(\Delta \mathrm{T})
$$

The expression of the quantity of heat exchanged in this case by the adsorber, the condenser and the evaporator are expressed as follows:

\subsection{Adsorber / condenser}

According to the theoretical thermodynamic cycle of adsorption solar refrigeration systems, the generation of vapor from the liquid state of the working fluid occurs in two different phases.

\subsubsection{Isosteric heating}

The adsorber receives a quantity of solar energy necessary for heating the adsorbent / adsorbate pair $\mathrm{Q}_{\mathrm{d} 1}$ expressed by:

$$
\mathrm{Q}_{\mathrm{d} 1}=\dot{\mathrm{m}}_{\mathrm{d}}\left(\mathrm{h}_{2}-\mathrm{h}_{1}\right)
$$

\subsubsection{Isobaric heating}

In this phase begins the generation of steam (desorption), the required energy $\mathrm{Q}_{\mathrm{d} 2}$ is:

$$
\mathrm{Q}_{\mathrm{d} 2}=\dot{\mathrm{m}}_{\mathrm{c}}\left(\mathrm{h}_{3}-\mathrm{h}_{2}\right)
$$

\subsection{Evaporator}

During the evaporation phase, the refrigerant which is the adsorbate in the case of the adsorption refrigeration system, passes from the liquid state to the vapor state by absorbing a quantity of heat from the medium to be cooled $\mathrm{Q}_{\mathrm{ev}}$ corresponds to:

$$
\mathrm{Q}_{\mathrm{e}}=\dot{\mathrm{m}}_{\mathrm{e}}\left(\mathrm{h}_{1}-\mathrm{h}_{4}\right)
$$

\subsection{System performance equation}

The expression of the COP will be defined as follows:

$$
\operatorname{COP}=\frac{\mathrm{Q}_{\mathrm{e}}}{\mathrm{Q}_{\mathrm{g}}}
$$

Within our case $\mathrm{Q}_{\mathrm{g}}$ is given by:

$$
\mathrm{Q}_{\mathrm{g}}=\mathrm{Q}_{\mathrm{d} 1}+\mathrm{Q}_{\mathrm{d} 2}
$$

By replacing (1) and (2) in (5):

$$
\mathrm{Q}_{\mathrm{g}}=\dot{\mathrm{m}}_{\mathrm{d}}\left(\mathrm{h}_{2}-\mathrm{h}_{1}\right)+\dot{\mathrm{m}}_{\mathrm{c}}\left(\mathrm{h}_{3}-\mathrm{h}_{2}\right)
$$

The final expression of the coefficient of performance becomes:

$$
\operatorname{COP}=\frac{\dot{\mathrm{m}}_{\mathrm{e}}\left(\mathrm{h}_{1}-\mathrm{h}_{4}\right)}{\dot{\mathrm{m}}_{\mathrm{d}}\left(\mathrm{h}_{2}-\mathrm{h}_{1}\right)+\dot{\mathrm{m}}_{\mathrm{c}}\left(\mathrm{h}_{3}-\mathrm{h}_{2}\right)}
$$

\section{WORKING CONSTRAINTS}

\subsection{Hypotheses}

In order to have an agreement between the chosen model and the considered unit, certain assumptions were imposed.

We consider that there is no heat loss to the outside environment.

- All the liquid present in the adsorber is evaporated (desorption) as well as the condensate stored in the container is assumed to be completely evaporated (adsorption).

- The flow rate of the fluid in each phase is assumed to be constant.

- The opening and closing of each valve are done at the end of each phase.

\subsection{Operating parameters}

Condensation and evaporation pressure: literature shows that condensation takes place at a pressure of 145 mbar to 216 mbar, while adsorption takes place at a pressure of $90 \mathrm{mbar}$ to 160 mbar $[18,24]$.

Our work consists in varying the pressure value in this interval to see the effect of condensing pressure on the COP 
and that for the two couples chosen.

Temperatures: the operating temperatures were chosen such that they are close to those found in the experimental units seen in the literature $[14,16]$.

The objective of this study is to investigate the COP variation as a function of operating temperatures and pressure as well as a comparative profitability study between the two pairs chosen: $\mathrm{AC} /$ methanol and zeolite / water.

\subsection{Data table}

The data required for the calculation software are presented in the Table 1 below:

Table 1. Calculation data

\begin{tabular}{ccc}
\hline Symbol & Parameter & Value \\
\hline$\dot{\mathrm{m}}_{\mathrm{c}}$ & Mass flow rate of condensate & $3.7 \mathrm{~m}^{3} / \mathrm{h}[14]$ \\
$\dot{\mathrm{m}}_{\mathrm{d}}$ & Desorption phase mass flow & $1.6 \mathrm{~m}^{3} / \mathrm{h}[14]$ \\
$\dot{\mathrm{m}}_{\mathrm{e}}$ & Evaporation phase mass flow & $2 \mathrm{~m}^{3} / \mathrm{h}[14]$ \\
$\mathrm{P}_{\mathrm{c}}$ & Condensing pressure & $0.21676 \mathrm{bar}[24]$ \\
$\mathrm{P}_{\mathrm{e}}$ & Evaporation pressure & $0.02872 \mathrm{bar}[24]$ \\
$\mathrm{T}_{\mathrm{a}}$ & Adsorption temperature & $16^{\circ} \mathrm{C}[16]$ \\
$\mathrm{T}_{\mathrm{e}}$ & Evaporating temperature & $-5^{\circ} \mathrm{C}[16]$ \\
$\mathrm{T}_{\mathrm{g}}$ & Generation temperature & $61^{\circ} \mathrm{C}[16]$ \\
$\mathrm{T}_{\mathrm{max}}$ & Maximum heating temperature & $82^{\circ} \mathrm{C}[16]$ \\
\hline
\end{tabular}

\section{RESULTS AND INTERPRETATION}

To facilitate the analysis of the effect of varying the operating parameters of different components of the solar adsorption refrigeration system on performance, a thermodynamic model was presented. Numerical analysis consists of obtaining the appropriate configurations and therefore making the improvements to the COP.

The simulations were conducted by using the EES (Engineering Equation Solver) software and certified by the laboratory of Telemen university. The method of solving the system equations which describes the thermodynamic cycle and the model is purely numerical and based on the residue method approved by the calculation software which mean that the number of equations must equal to the number of variables and takes into consideration the thermodynamic adsorption cycle presented by the pressure and temperature parameters at each point of the diagram (Figure 2) and from there the quantities of heat exchanged can be determined and represented as a function of the mass enthalpy at this point. by knowing the thermodynamic parameters at each point of the cycle and the diagram (Figures 1 and 2), the software can determine the associated amount of heat then use it in the thermodynamic equations describing the performance of the system. And by varying each time the thermodynamic parameters of the cycle and even the working pair, we conduct to the results obtained.

In this study, we respectively discuss the effect of: (1) the maximum temperature $T_{\max }(2)$ the evaporation temperature $T_{e}$ (3) the generation temperature $T_{g}(4)$ the condensing pressure $P_{c}$ as well as the choice of the couple adsorbent / adsorbate on the COP. Calculation data is shown in Table 1.

\subsection{Model validation}

The values of the coefficient of performance COP as a function of the maximum temperature reached during the heating of the adsorption bed for the AC / methanol couple and those calculated by Douss \& Meunier [16] are presented in Table 2. The figure shows a reasonable agreement between the results although the COP shows a slight difference, which can be a consequence of not taking into account the thermal losses present in each phase and the difference between the operating conditions taken in each model.

Table 2. The COP calculated by the model and by Douss \& Meunier [16]

\begin{tabular}{ccc}
\hline $\mathbf{T}_{\max }{ }^{\circ} \mathbf{C}$ & $\mathbf{C O P}_{\text {model }}$ & $\mathbf{C O P}_{\text {douss\&meunier }}$ \\
\hline 70 & 0.496 & 0.49 \\
75 & 0.417 & 0.5 \\
80 & 0.359 & 0.51 \\
90 & 0.281 & 0.51 \\
110 & 0.195 & 0.49 \\
130 & 0.149 & 0.47 \\
\hline
\end{tabular}

\subsection{Effect of generation temperature}

The effects of the generation temperature $T_{g}$ on the coefficient of performance are shown in Figure 3. From the figure, it is noticed that the COP increases with the increase in the generation temperature and that for the two pairs used $\mathrm{AC}$ / methanol and zeolite / water. The reason is that the mass of the adsorbate generated is proportional at the generation temperature, in fact, increasing the generation temperature ensures better heat transfer performance at the adsorption bed level, which gives a greater amount of adsorbed mass and subsequently an increase in COP.

In addition, it is found that the change in COP as a function of the generation temperature is clearly different in the two cases of the pair type. The COP varies rapidly with the generation temperature in the case of the $\mathrm{AC} /$ methanol pair and reaches a maximum $\mathrm{COP}$ of 0.45 at $\mathrm{T}_{\mathrm{g}}=80^{\circ} \mathrm{C}$. on the other hand, in the case of the zeolite / water pair, the COP varies slowly and reaches a maximum value of around 0.15 .

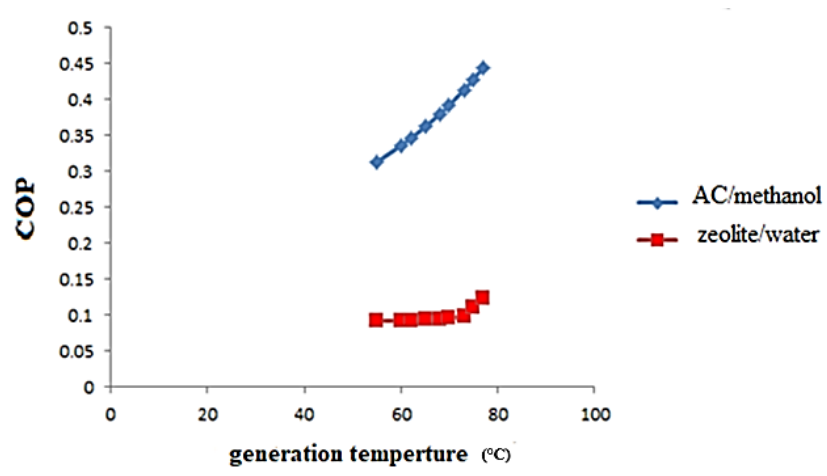

Figure 3. Effect of the generation temperature $T_{g}$ and type of the pair on the COP

\subsection{Effect of evaporating temperature}

Figure 4 shows the effect of varying the evaporating temperature $\mathrm{T}_{\mathrm{ev}}$ on the performance of the system. As can be seen in the figure, the COP decreases as the evaporating temperature increases. In addition, the COP in the case of the $\mathrm{AC} /$ methanol pair decreases rapidly in comparison with the zeolite / water pair. In the first case the COP reaches 0.09 at $\mathrm{T}_{\mathrm{ev}}=10^{\circ} \mathrm{C}$ and 0.01 in the second case for the same temperature. The results also show that the $\mathrm{AC} /$ methanol pair 
is more profitable in comparison with the zeolite / water pair. In the first case the COP reaches its maximum value of 0.35 at $\mathrm{T}_{\mathrm{ev}}=-5^{\circ} \mathrm{C}$ while in the other case the maximum value of COP is of the order of 0.1 for the same evaporation temperature.

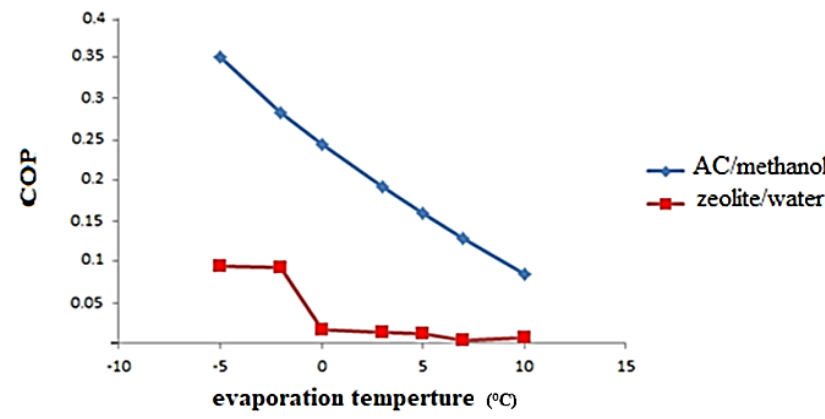

Figure 4. COP variation as a function of the evaporation temperature $\mathrm{T}_{\mathrm{ev}}$ and the working pair type

\subsection{Effect of the maximum temperature}

A number of simulations have been carried out by varying the temperature of the maximum adsorption bed during the heating phase. Figure 5 shows the results for the two types of couples used. The figure suggests that the COP decreases when the maximum heating temperature increase. the figure also shows that the optimum COP reached is 0.49 in the case of the $\mathrm{AC} /$ methanol couple for a temperature of $70^{\circ} \mathrm{C}$ and 0.093 in the case of the zeolite / water couple. As with high heating temperatures, the COP decreases slower in the second case, reaching lower COPs.

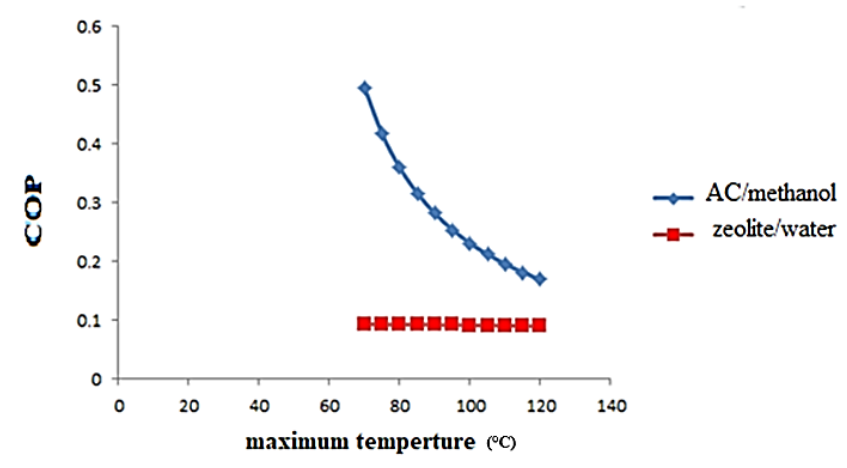

Figure 5. Variation of COP with maximum temperature $T_{g}$ and the working pair type

\subsection{Effect of condensing pressure}

Figure 6 shows the variation in the effect of condensing pressure on the coefficient of performance. The results showed that the COP is slightly affected by the variation of the condensing pressure between $100 \mathrm{mbar}$ and $270 \mathrm{mbar}$. This corresponds to a maximum COP of 0.346 in the case of the AC / methanol pair and 0.0972 in the case of the zeolite / water pair. Another thing can be seen in the figure is the influence of adsorbent / adsorbate pair type. This is present in this study with the use of the zeolite / water and AC / methanol pair, the latter seems to be the most favourable given the high values of COP given in each simulation under such imposed operating conditions of pressure and temperature and with this type of system and these components illustrated above. In addition, the profitability of the adsorbent / adsorbate couple can be affected by the components of the solar adsorption system used and the operating conditions and the incident solar flux.

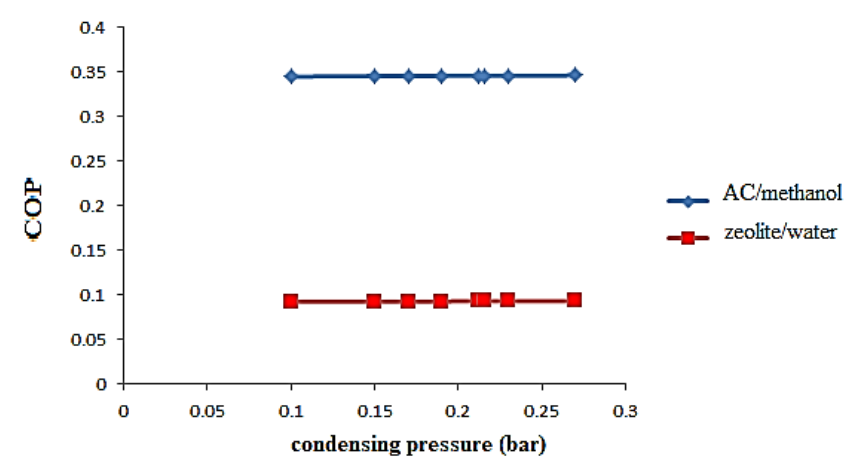

Figure 6. Effect of condensing pressure $\mathrm{P}_{\mathrm{c}}$ and the working pair type on the COP

\section{CONCLUSIONS}

The effects of variations in the operating parameters of a refrigeration system based on AC / methanol and zeolite / water pairs is studied using a thermodynamic equilibrium model describing the amount of heat exchanged in each component of the solar adsorption refrigeration system.

The following conclusions can be drawn:

- The performance of the system in terms of COP varies almost linearly with the generation temperature $\mathrm{T}_{\mathrm{g}}$. The coefficient of performance increases remarkably if $\mathrm{T}_{\mathrm{g}}$ is increased.

- $\quad$ The COP decreases with the increase in the evaporating temperature $T_{e}$ for fixed operating parameters. A similar effect is observed when the maximum heating temperature $\mathrm{T}_{\max }$ is increased.

- The condensation pressure does not present a determining factor in this study because the COP is slightly affected by its evolution and it is observed that the two pairs used AC / methanol and zeolite / water give the same variation while the effect was different. which appears in a COP of 0.346 in the case of the AC / methanol couple and 0.0972 in the other case.

- This study has shown that a solar adsorption refrigeration machine operating with the $\mathrm{AC} /$ methanol pair is more profitable than a machine operating with the zeolite / water pair, which justifies the wide use and commercialization of this pair in this field in the face of other.

This study evaluated the direction of variation of COP as a function of the operating parameters with a comparison between the two pairs used in this adsorption solar refrigeration system and their effects on performance, which leads to an improved system with a COP comparable to values reported in the literature. These results are therefore useful for further research into performance improvements in this area and with this type of systems.

\section{REFERENCES}

[1] Benramdane, M., Abboudi, S., Ghernaout, M. (2019). Contribution to the simulation and parametric analysis of the operation of a solar concentration thermal installation. 
International Journal of Heat and Technology, 37(2): 446-456. https://doi.org/10.18280/ijht.370210

[2] Magrini A., Lazzari S., Marenco L., Guazzi G. (2017). A procedure to evaluate the most suitable integrated solutions for increasing energy performance of the building's envelope, avoiding moisture problems. International Journal of Heat and Technology, 35(4): 689-699. https://doi.org/10.18280/ijht.350401

[3] Aliane, A., Abboudi, S., Seladji, C., Guendouz, B. (2018). An illustrated review on solar absorption cooling experimental studies. Renewable and Sustainable Energy Reviews, 65:

443-458. https://doi.org/10.1016/j.rser.2016.07.012

[4] Lu, Z.S., Wang, R.Z., Xia, Z.Z., Lu, X.R., Yang, C.B., Ma, Y.C., Ma, G.B. (2013). Study of a novel solar adsorption cooling system and a solar absorption cooling system with new CPC collectors. Renewable Energy, 50: 299-306. https://doi.org/10.1016/j.renene.2012.07.001

[5] Siddiqui, O.K., Yilbas, B.S. (2013). Solar absorption heating in horizontal channel: Influence of absorbing plate location on thermal performance. Energy Conversion and Management, 74: 140-148. https://doi.org/10.1016/j.enconman.2013.05.009

[6] Lecuona, A., Ventas, R., Vereda, C., López, R. (2015). Absorption solar cooling systems using optimal driving temperatures. Applied Thermal Engineering, 79: 140148

https://doi.org/10.1016/j.applthermaleng.2014.10.097

[7] Dieng, A.O., Wang, R.Z. (2001). Literature review on solar adsorption technologies for ice-making and air conditioning purposes and recent developments in solar technology. Renewable and Sustainable Energy Reviews, 5(4): $\quad 313-342 . \quad$ https://doi.org/10.1016/S13640321(01)00004-1

[8] Fernandes, M.S., Brites, G.J.V.N., Costa, J.J., Gaspar, A.R., Costa, V.A.F. (2014). Review and future trends of solar adsorption refrigeration systems. Renewable and Sustainable Energy Reviews, 39: 102-123. https://doi.org/10.1016/j.rser.2014.07.081

[9] Kattakayam, T.A., Srinivasan, K. (2000). Thermal performance characterization of a photovoltaic driven domestic refrigerator. International Journal of Refrigeration, 23(3): 190-196. https://doi.org/10.1016/S0140-7007(99)00049-3

[10] Li, Y., Zhang, G., Lv, G.Z., Zhang, A.N., Wang, R.Z. (2015). Performance study of a solar photovoltaic air conditioner in the hot summer and cold winter zone. Solar Energy, 117: 167-179. https://doi.org/10.1016/j.solener.2015.04.015

[11] Anyanwu, E.E. (2003). Review of solid adsorption solar refrigerator I: An overview of the refrigeration cycle. Energy Conversion and Management, 44(2): 301-312. https://doi.org/10.1016/S0196-8904(02)00038-9

[12] Alghoul, M.A., Sulaiman, M.Y., Sopian, K., Azmi, B.Z. (2009). Performance of a dual purpose solar continuous adsorption system. Renewable Energy, 34(3): 920-927. https://doi.org/10.1016/j.renene.2008.05.037

[13] Bataineh, K., Taamneh, Y. (2016). Review and recent improvements of solar sorption cooling systems. Energy and Buildings, 128: 22-37. http://dx.doi.org/10.1016/j.enbuild.2016.06.075

[14] Ghilen, N., Gabsi, S., Messai, S., Benelmir, R., El Ganaoui, M. (2016). Performance of silica gel-water solar adsorption cooling system. Case Studies in Thermal
Engineering,

$8:$

http://dx.doi.org/10.1016/j.csite.2016.07.002

$337-345$.

[15] Xu, S. (2011). Simulation on a new adsorption bed about adsorption refrigeration driven by solar energy. Procedia Engineering, 15: 3865-3869. https://doi.org/10.1016/j.proeng.2011.08.723

[16] Douss, N., Meunier, F. (1988). Effect of operating temperatures on the coefficient of performance of active carbon-methanol systems. Heat Recovery Systems \& CIIP, 8(5): 383-392. https://doi.org/10.1016/08904332(88)90042-7

[17] Leite, A.P.F., Daguenet, M. (2000). Performance of a new solid adsorption ice maker with solar energy regeneration. Energy Conversion \& Management, 41(15): $1625-1647$ 8904(00)00011-X

[18] Ambarita, H., Kawai, H. (2016). Experimental study on solar-powered adsorption Refrigeration cycle with activated alumina and activated Carbon as adsorbent. Case Studies in Thermal Engineering, 7: 36-46. https://doi.org/10.1016/j.csite.2016.01.006

[19] Brites, G.J.V.N., Costa, J.J., Costa, V.A.F. (2016). Review and future trends of solar adsorption refrigeration systems. Renewable Energy, 86: 238-250.

[20] Jaiswal, A.K., Mitra, S., Dutta, P., Srinivasan, K., Murthy, S.S. (2016). Influence of cycle time and collector area on solar driven adsorption chillers. Solar Energy, 136: 450-459. https://doi.org/10.1016/j.solener.2016.07.023

[21] Cherrad, N. (2018). Modélisation numérique des températures limites du cycle des machines frigorifiques solaires à adsorption. Le 5ème Séminaire International sur les Energies Nouvelles et Renouvelables, Unité de Recherche Appliquée en Energies Renouvelables.

[22] Fernandes, M.S., Brites, G.J.V.N., Costa, J.J., Gaspar, A.R., Costa, V.A.F. (2014). Review and future trends of solar adsorption refrigeration systems. Renewable and Sustainable Energy Reviews, 39: 102-123.

[23] Chekirou, W., Chikouche, A., Boukheit, N., Karaali, A., Phalippou, S. (2014). Dynamic modelling and simulation of the tubular adsorber of a solid adsorption machine powered by solar energy. International Journal of Refrigeration, 39: 137-151. http://dx.doi.org/10.1016/j.ijrefrig.2013.11.019

[24] Chekirou, W., Boukheit, N., Karaali, A. (2016). Dynamic model of heat and mass transfer in rectangular adsorber of a solar adsorption machine. Journal of Physics: Conference $\quad$ Series, 758: 012006. http://iopscience.iop.org/1742-6596/758/1/012006

[25] Chua, H.T., Nga, K.C., Maleka, A., Kashiwagib, T., Akisawab, A., Saha, B.B. (1999). Modeling the performance of two-bed, sillica gel-water adsorption chillers. International Journal of Refrigeration, 22(3): 194-204. https://doi.org/10.1016/S0140-7007(98)000632

[26] Tubreoumya, G.C., Dissa, A.O., Tiendrebeogo, E.S., Chesneau, X., Compaoré, A., Haro, K., Konseibo, C.D., Zeghmati, B., Koulidiati, J. (2017). Contribution to the modeling of a solar adsorption refrigerator under the climatic conditions of Burkina Faso. Energy and Power Engineering, $\quad 9(2)$ :

119-135. https://doi.org/10.4236/epe.2017.92010

[27] Liu, Y.M., Yuan, Z.X., Wen, X., Du, C.X. (2021). Evaluation on performance of solar adsorption cooling of 
silica gel and SAPO-34 zeolite. Applied Thermal Engineering, $\quad 182(4)$ : 116019. https://doi.org/10.1016/j.applthermaleng.2020.116019

[28] Ji, X., Li, M., Fan, J., Zhang, P., Luo, B., Wang, L. (2014). Structure optimization and performance experiments of a solar-powered finned-tube adsorption refrigeration system. Applied Energy, 113: 1293-1300. http://dx.doi.org/10.1016/j.apenergy.2013.08.088

[29] Habib, K., Saha, B.B., Koyama, S. (2014). Study of various adsorbent refrigerant pairs for the application of solar driven adsorption cooling in tropical climates. Applied Thermal Engineering, 72: 266-274.

[30] Wang, Y., Li, M., Du, W., Ji, X., Xu, L. (2018). Experimental investigation of a solar-powered adsorption refrigeration system with the enhancing desorption. Energy Conversion and Management, 155: 253-261.

http://dx.doi.org/10.1016/j.enconman.2017.10.065

[31] Lu, Z.S., Wang, R.Z., Xia, Z.Z., Lu, X.R., Yang, C.B., Ma, Y.C., Ma, G.B. (2013). Study of a novel solar adsorption cooling system and a solar absorption cooling system with new CPC collectors. Renewable Energy, 50: 299-306. https://doi.org/10.1016/j.renene.2012.07.001

\section{NOMENCLATURE}

$\mathrm{CP}$

COP

$\mathrm{h}$

$\dot{\mathrm{m}}$

$P$

Q

$\mathrm{T}$

$\mathrm{X}$

\section{Subscripts}

a

c

$\mathrm{Ch}$

i

e

g

$\min$

$\max$

o

W specific heat, $\mathrm{J} \mathrm{kg}^{-1} \cdot \mathrm{K}^{-1}$

coefficient of performance

specific enthalpy, $\mathrm{kJ} \mathrm{kg}^{-1}$

mass flow rate, kg.s ${ }^{-1}$

Pressure, bar

heat, $\mathrm{kW}$

temperature, ${ }^{\circ} \mathrm{C}$

concentration, $\mathrm{kg}$ adsorbate $/ \mathrm{kg}$ adsorbent

adsorption

condensation

adsorber

In

evaporation

generation

minimum

maximum

out

water 